Research Article

\title{
Evaluation of Biophysical Interaction between Newly Synthesized Pyrazoline Pyridazine Derivative and Bovine Serum Albumin by Spectroscopic and Molecular Docking Studies
}

\author{
Abdulrahman A. Al-Mehizia $\mathbb{D}^{1},{ }^{1}$ Ahmed H. Bakheit $\mathbb{D}^{1,2}$ Seema Zargar $\mathbb{D}^{3}{ }^{3}$ \\ Mashooq A. Bhat $\mathbb{D},{ }^{1}$ Majid Mohammed Asmari, ${ }^{4}$ and Tanveer A. Wani ${ }^{1}{ }^{1}$ \\ ${ }^{1}$ Department of Pharmaceutical Chemistry, College of Pharmacy, King Saud University, P.O. Box 2457, \\ Riyadh 11451, Saudi Arabia \\ ${ }^{2}$ Department of Chemistry, Faculty of Science and Technology, Al-Neelain University, Khartoum, Sudan \\ ${ }^{3}$ Department of Biochemistry, College of Science, King Saud University, PO Box 22452, Riyadh 11451, Saudi Arabia \\ ${ }^{4}$ Research Center, College of Pharmacy, King Saud University, P.O. Box: 2457, Riyadh 11451, Saudi Arabia
}

Correspondence should be addressed to Tanveer A. Wani; twani@ksu.edu.sa

Received 25 February 2019; Revised 6 May 2019; Accepted 22 May 2019; Published 16 June 2019

Academic Editor: Jose S. Camara

Copyright (c) 2019 Abdulrahman A. Al-Mehizia et al. This is an open access article distributed under the Creative Commons Attribution License, which permits unrestricted use, distribution, and reproduction in any medium, provided the original work is properly cited.

\begin{abstract}
In this research, the pyrazoline pyridazine derivative 7-methyl-2-phenyl-4-(3,4,5-trimethoxyphenyl)-2H-pyrazolo[3,4-d] pyridazine (5d) was studied for its interaction with bovine serum albumin (BSA). Various spectroscopic techniques along with molecular docking analysis were utilized to understand the mechanism of interaction. The quenching of BSA fluorescence by using investigational drug 5d was the basic principle for the methodology. Spectrofluorometric methods and UV-absorption studies were conducted for exploration of the $\mathbf{5 d}$ and BSA binding mechanism. The fluorescence quenching mechanism involved in BSA and 5d interaction was static quenching, and a complex formation also occurred between them. Both enthalpy and entropy attained positive values suggesting involvement of hydrophobic forces in BSA and 5d interaction. The Förster distance of $2.23 \mathrm{~nm}$ was calculated by fluorescence resonance energy transfer (FRET). An alteration in BSA secondary structure was proven from the conformational studies of BSA-5d interaction. This binding interaction study provided a basis to comprehend the binding interaction between $\mathbf{5 d}$ and BSA. These results provided information about sites of BSA involved in its interaction with $\mathbf{5 d}$.
\end{abstract}

\section{Introduction}

Prostaglandin biosynthesis (cyclooxygenases; COXs) are inhibited by nonsteroidal anti-inflammatory drugs $[1,2]$. Arachidonic acid is broken down by the COX enzymes to produce prostaglandins which have a number of important physiological functions. The main use of nonsteroidal antiinflammatory drugs (NSAIDs) is to alleviate the pain and inflammation due to certain diseased states. COX-1 isoform is mainly induced under all physiological conditions, whereas in carcinogenesis and inflammatory responses, COX-2 is induced [3]. The synthesis of COX-2 inhibitors has aided in the improved management of pain, inflammation, and other associated disorders. In addition to the effective management of certain diseased states, COX-2 inhibitors have established enhanced gastrointestinal tolerability and fewer side effects in comparison with the nonselective NSAIDs $[4,5]$.

However, a long-term use of either selective COXinhibitors or nonselective NSAIDs can lead to serious cardiovascular events $[6,7]$. In order to overcome the side effects of certain drugs, their structures are either modified or new drugs are discovered with the aim to produce safe and therapeutically competent drugs [8]. 
Pyrazole scaffolds possess anti-inflammatory [9-12], analgesic [13], neuroprotective [14], antidepressant, and anticonvulsant activities $[15,16]$. Some pyrazoline derivatives that possess analgesic activity and antiinflammatory activity are phenylbutazone, celecoxib, and deracoxib.

In this context, $\mathbf{5 d}$ (Figure 1) was synthesized in-house in the medicinal chemistry laboratory with the aim of finding a new COX-2 inhibitor which might possess better tolerability and fewer side effects [17]. The synthesized compound 5d intensely downregulated COX-2 induction and suppressed its expression up to $42.8 \%$ compared to lipopolysaccharide(LPS-) stimulated controlled cells (100\% expression). Also, a strong inhibition of LPS-induced nitric oxide synthase expression was observed with 5d [17].

In the systemic circulation, the synthesized drug has to come in contact with proteins, thus leading to a drug-protein interaction. Serum albumin protein present in blood maintains the osmotic pressure (colloidal) and transports biomolecules such as steroids, fatty acids, and hormones inside the body [18-20]. Drug molecules also interact with albumin in serum and are also carried by it in the systemic circulation. The pharmacodynamic and pharmacokinetic (absorption, distribution, metabolism, and excretion) properties of a drug are highly influenced by the proteindrug interaction $[1,2]$. A reduced lifetime of a ligand is due to its weak binding to albumin and can also lead to its poor distribution. However, a strong binding interaction with the ligand leads to reduced free ligand concentrations. The study and understanding of binding interaction between ligand and albumin at the molecular level is therefore crucial in evaluating the biological activity of the ligand. Thus, the binding mechanism of drug with albumin, and its distribution needs to be investigated [20-23].

Since both the BSA and human serum albumin (HSA) are homologous in structure [2], and due to low procurement cost of BSA, it is a popular approach to substitute HSA with BSA to represent the serum albumins in proteinligand interaction studies. The binding affinity and mode in the BSA-5d system were determined using fluorescence spectroscopy.

The fluorescence quenching studies including synchronous and three-dimensional fluorescence and UV spectroscopic studies were conducted to comprehend the binding mechanism between BSA and 5d. Binding site of 5d on BSA was established with ligand displacement studies using site probe ligands phenylbutazone for site I and ibuprofen for site II $[24,25]$. Molecular docking study for BSA and 5d interaction was also performed to corroborate with experimental results. The results of this study will be helpful in conducting the pharmacokinetic studies of $5 d$.

\section{Materials and Methods}

2.1. Materials. Compound 5d was synthesized in-house $[17,21]$. The other materials procured were as follows: fatty acid-free BSA (Sigma Aldrich; USA), ibuprofen, and phenylbutazone (National Scientific Company; KSA).

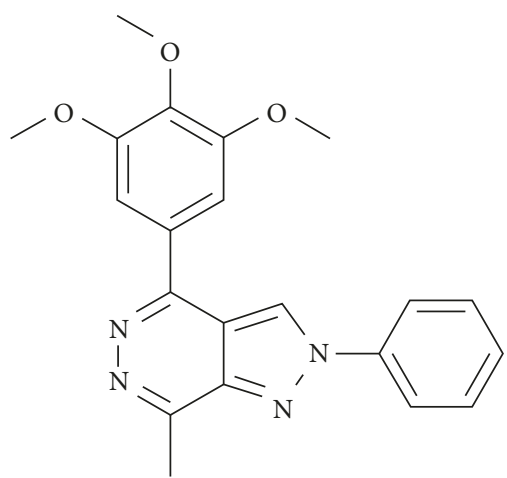

Figure 1: Chemical structure of 7-methyl-2-phenyl-4-(3,4,5-trimethoxyphenyl)-2H-pyrazolo[3,4-d]pyridazine (5d).

2.2. Sample Preparation. The BSA stock was prepared in phosphate buffer saline (PBS; pH 7.4). The stock of 5d $(5 \mathrm{mM})$ was prepared in acetonitrile and was diluted with PBS pH 7.4.

2.3. UV-Vis Absorption Spectra. The Shimadzu UV-1800 (Shimadzu Japan) spectrophotometer was used to record the UV-Vis absorption spectra. The spectra for BSA both in absence and presence of different concentrations of $\mathbf{5} \mathbf{d}$ were obtained. The measurements were performed at room temperature and fixed BSA concentration.

2.4. Fluorescence Spectroscopy. The fluorescence spectrometer (JASCO Model FP-8200) was used to record the fluorescence spectra. The spectra were acquired for BSA (fixed concentration) in absence and presence of different $\mathbf{5 d}$ concentrations. The fluorescence spectra were acquired at 298,303 , and $310 \mathrm{~K}$. The spectra were acquired at $\lambda_{\mathrm{ex}}=280 \mathrm{~nm}$ and $\lambda_{\mathrm{em}}=300-500 \mathrm{~nm}$.

2.5. Fluorescence Quenching Measurement. The spectra were recorded for BSA in presence of various concentrations of $\mathbf{5 d}$ $(0-18 \mu \mathrm{M})$. The concentration of BSA $(1.5 \mu \mathrm{M})$ was held constant for all the measurements. The BSA fluorescence is quenched by 5d. Stern-Volmer equation was used for fluorescence data evaluation:

$$
\frac{F_{0}}{F}=1+K_{\text {sv }}[Q]=1+K_{\mathrm{q}} \tau_{0}[Q],
$$

where $F$ and $F_{0}$ are the fluorescence intensity (FI) of BSA in presence and absence of ligand $\mathbf{5 d} . K_{\mathrm{sv}}$ represents SternVolmer quenching constant; $K_{\mathrm{q}}$ is the bimolecular quenching rate constant. $[Q]$ is the quencher concentration, and " $\tau_{0}$ " is fluorophore's average life time.

Double-log regression plot was used to obtain the binding constant of BSA and $\mathbf{5 d}$. The following equation is used to express the molecular equilibrium:

$$
\log \frac{\left(F_{0}-F\right)}{F}=\log K_{\mathrm{b}}+n \log [Q] .
$$

In (2) " $n$ " is the binding site number and $K_{\mathrm{b}}$ is the binding constant. 
The thermodynamic study helps to determine the type of interaction and bonds involved in the interaction. The standard Gibbs free energy change is given as

$$
\Delta G^{0}=\Delta H^{0}-T \Delta S^{0}=-R T \ln K_{\mathrm{b}} .
$$

2.6. Synchronous Fluorescence (SF) and Binding Site Probe Experiment. The SF spectroscopy helps in determination and characterization of microenvironmental changes around the amino acid residues tyrosine (Tyr) and tryptophan (Trp). In the BSA-5d system, these changes were recorded using a constant difference of $\Delta \lambda=60$ and $15 \mathrm{~nm}$ between excitation and emission wavelengths. These SF spectra were attained at $298 \mathrm{~K}$. Drug displacement studies were conducted with phenylbutazone and ibuprofen to establish BSA binding sites for $\mathbf{5 d}$.

\subsection{Three-Dimensional (3D) Fluorescence Spectroscopy.} These spectra help in obtaining information about the chromophore. The data aid in finding any conformational alterations in protein (BSA) transpired by interaction with ligand (5d). 3D spectra were acquired for BSA and BSA-5d system.

2.8. Molecular Docking. Molecular docking was done on the molecular operating environment (MOE). The analysis was executed with BSA crystal structure (cocrystallized with naproxen, PDB ID: 4OR0). The 5d structure was drawn within the MOE software. The energy minimization was achieved from default field force parameters of MMFF94X, eps $=r$, and cutoff (8-10). Default docking parameter triangle matcher was used. The scoring function 1 was put to London $\mathrm{dG}$, and the function 2 was put to GBVI/WSA dG. The most appropriate interaction was designated as per the root mean square values obtained [21].

\section{Results and Discussion}

3.1. Fluorescence Quenching Studies. Protein and ligand interaction can be understood with fluorescence quenching studies of proteins by ligands. The fluorescent behavior of BSA is due to the amino acid residues, Trp, Tyr and Phe residues, that are embedded in it. The ratio of fluorescence intensity of the three amino acids present in BSA is $100: 9$ : 0.5 for Trp, Tyr, and Phe, respectively [26]. Thus, the two Trp residues present in BSA are mainly responsible for its fluorescence. The residue Trp-134 is on the subdomain IB surface, whereas Trp-213 is in the subdomain IIA hydrophobic pocket. The BSA fluorescence because of Trp and Tyr residues has been used to study the conformation changes and ligand interactions. The quantum yield of Tyr is almost the same as Trp; however, the indole group of Trp in proteins is mainly liable for UV absorbance $(\sim 280 \mathrm{~nm})$ and emission $(\sim 350 \mathrm{~nm})$. The excitation spectra measured at $\lambda_{\mathrm{em}}=340 \mathrm{~nm}$ (Figure 2(a)) for BSA and BSA-5d were compared, and they provided information of the effect of $\mathbf{5 d}$ concentration increase on the Trp behavior [27].
The BSA concentration was held constant. $\mathbf{5} \mathbf{d}$ concentration was varied in different samples to obtain the fluorescence quenching spectra (Figure 2(b)). The FI of BSA reduced as the concentrations of $\mathbf{5} \mathbf{d}$ increased. A small red shift of $1 \mathrm{~nm}$ in the $\lambda_{\text {(emissions) }}$ was detected which implied that the amino acids were present in a polar environment and had a higher exposure to the solvents [28]. The quenching mechanisms are classified as static and dynamic quenching. The dynamic quenching and static quenching are differentiated on the basis of effect of temperature and viscosity on them. In dynamic quenching, the quenching constant rises with temperature due to high diffusion and collision quenching. In contrast, higher temperature causes instability of the complex and lower quenching constants in the static quenching. Thus, lower quenching constant values at higher temperatures indicate formation of a nonfluorescent complex and static quenching mechanism [29].

Stern-Volmer equation (1) is used to interpret the quenching mechanism in the protein-ligand interaction. Low $K_{\text {sv }}$ was observed at high temperatures (Figure 3(a)), thus inferring formation of BSA-5d ground-state complex (Table 1). Similarly, $K_{\mathrm{q}}$ (collision quenching constant) also helps in elucidation of quenching mechanism and is given as

$$
K_{\mathrm{q}}=\frac{K_{\mathrm{sv}}}{\tau} .
$$

The maximum value of $K_{\mathrm{q}}$ for a dynamic quenching process is $2 \times 10^{10} \mathrm{~L} \cdot \mathrm{mol}^{-1} \cdot \mathrm{s}^{-1}[25,30]$, and the values for the BSA-5d system were quite greater than the maximum value (Table 1). These results suggest that static quenching was involved in BSA-5d interaction.

3.2. Binding Constant and Number of Binding Sites. From equation (2), the plot $\log \left[\left(F_{0} / F\right)-1\right]$ vs $\log [Q]$ yielded a straight line, where the binding stoichiometry $(n)$ equals the slope and $K_{\mathrm{b}}$ (binding constant) from the intercept (Figure 3(b)) [31]. The binding constant at different temperatures and " $n$ " values are given in Table 2 [32].

Site specific markers were used for identification of binding site studies using competitive binding experiments. The specific site markers phenylbutazone (PBT) for site I and ibuprofen (IBF) for site II of BSA were used to study the binding site involved in the competition with $\mathbf{5 d}$ (Figure 4) $[24,25]$. The spectra were recorded for BSA in presence of site marker holding the concentration of both constants and increasing $\mathbf{5 d}$ concentrations at room temperature (Figure 3(d)). A huge reduction of the binding constant of the BSA-5d system with addition of either of the site markers PBT and IBF was observed (Table 3). As the binding constants decreased in either of the PBT and IBF and the decrease was more in presence of PBT than IBF, it was inferred that $\mathbf{5 d}$ might be binding to both the BSA at sites I and II and more preferably to site I.

3.3. Thermodynamic Parameters. Four main forces, namely, hydrophobic interactions, hydrogen bonding, and van der Waals and electrostatic interaction forces are involved in the ligand-protein interaction [33-35]. The thermodynamic 


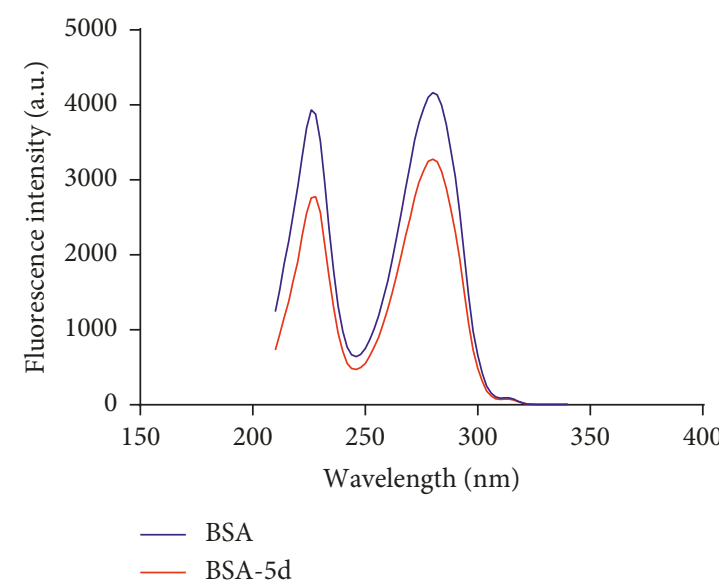

(a)

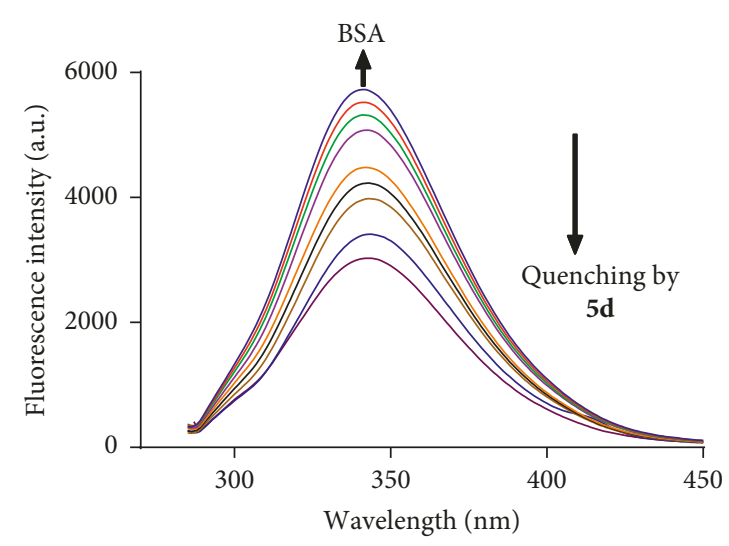

(b)

Figure 2: (a) Fluorescence excitation spectra of BSA $=(1.5 \mu \mathrm{M})$ and $\mathbf{5 d}(6.5 \mu \mathrm{M})$ measured at $\lambda_{\mathrm{em}}=350 \mathrm{~nm}$. (b) Fluorescence spectra of BSA $(1.5 \mu \mathrm{M})$ and $\mathbf{5 d}(0-18 \mu \mathrm{M})$ at $298 \mathrm{~K}$.

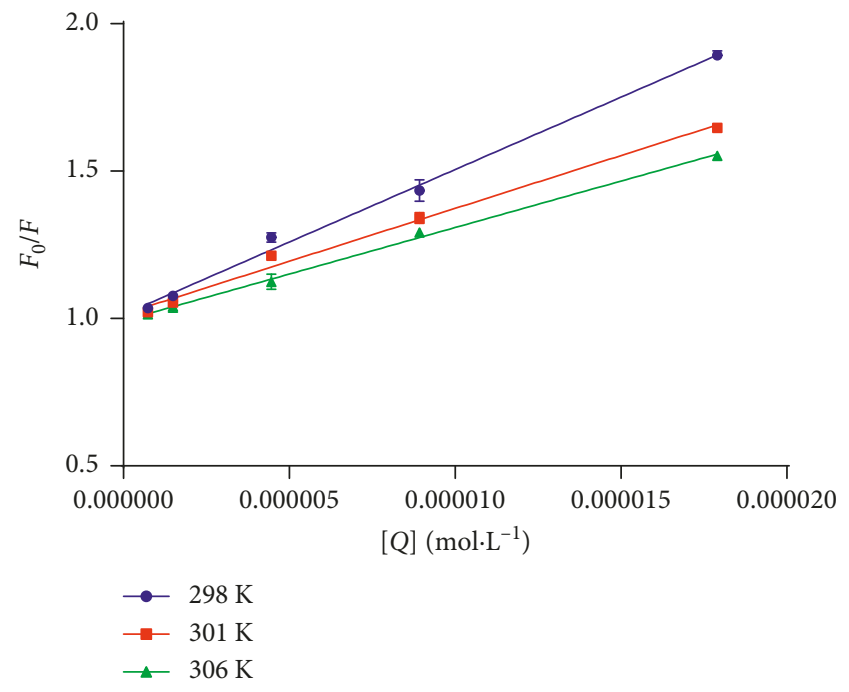

(a)

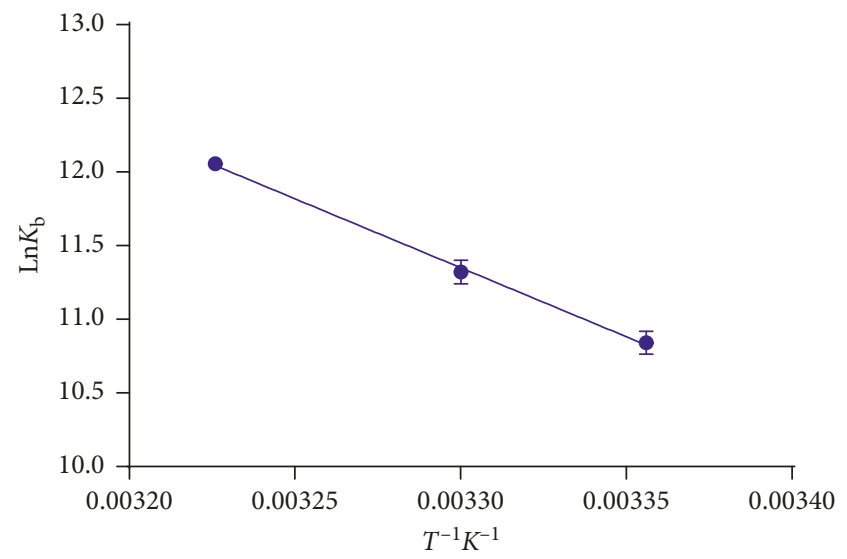

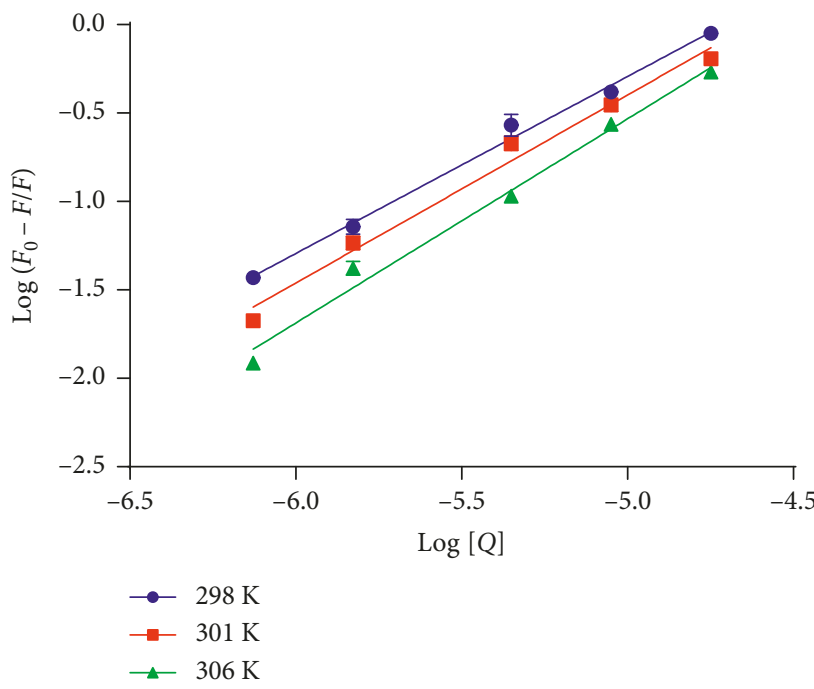

(b)

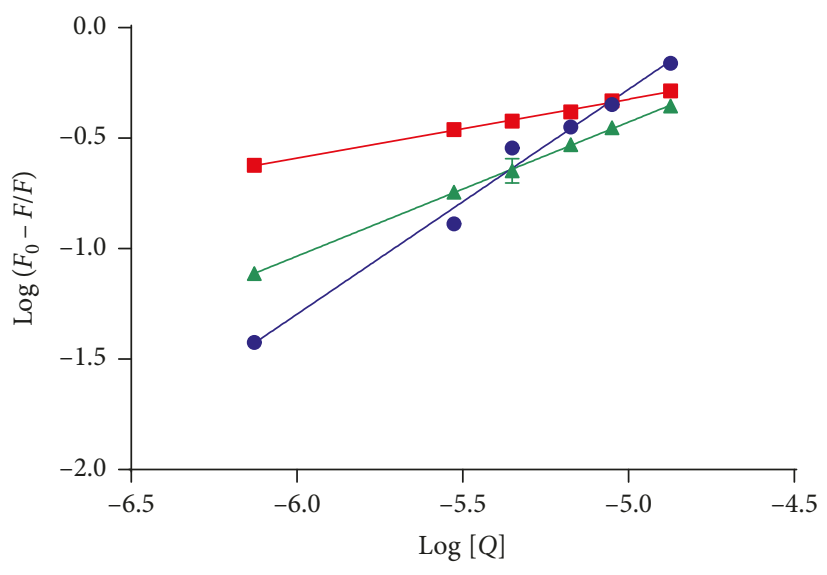

$$
\begin{aligned}
& \multimap \text { BSA } \\
& \because \text { PBT } \\
& \longleftarrow \text { IBF }
\end{aligned}
$$

(c)

Figure 3: (a) Stern-Volmer plot for the quenching of BSA by 5d at 298/303/310 K. (b) The plot of $\log \left[\left(F_{0}-F\right) / F\right]$ versus $\log [\mathrm{Q}]$ for quenching process of 5d with BSA at 298/303/310 K. (c) Van't Hoff plots for the binding interaction of 5d with BSA. (d) The plot of log $\left[\left(F_{0}-F\right) / F\right]$ versus $\log [\mathrm{Q}]$ for quenching process of $\mathbf{5 d}$ with BSA in presence of site markers phenylbutazone and ibuprofen at $298 \mathrm{~K}$. 
TABLE 1: BSA-5d system: quenching constant $K_{\mathrm{sv}}$ and biomolecular quenching constant $K_{\mathrm{q}}$.

\begin{tabular}{lccc}
\hline $\mathrm{T}(\mathrm{K})$ & $R$ & $K_{\mathrm{sv}} \pm \mathrm{SD} \times 10^{4}\left(\mathrm{M}^{-1}\right)$ & $K_{\mathrm{q}} \times 10^{12}\left(\mathrm{M}^{-1} \cdot \mathrm{S}^{-1}\right)$ \\
\hline 298 & 0.9947 & $4.91 \pm 0.03$ & 4.91 \\
303 & 0.9919 & $3.58 \pm 0.03$ & 3.58 \\
310 & 0.9964 & $3.15 \pm 0.04$ & 3.15 \\
\hline
\end{tabular}

TABLE 2: BSA-5d system: binding parameters and thermodynamic parameters.

\begin{tabular}{lccccc}
\hline $\mathrm{T}(\mathrm{K})$ & $K_{\mathrm{b}} \pm \mathrm{SD}$ & $n$ & $\Delta G^{\circ} \pm \mathrm{SD}\left(\mathrm{kJ} \cdot \mathrm{mol}^{-1}\right)$ & $\Delta H^{\circ} \pm \mathrm{SD}\left(\mathrm{kJ} \cdot \mathrm{mol}^{-1}\right)$ & $\Delta S^{\circ} \pm \mathrm{SD}\left(\mathrm{J} \cdot \mathrm{mol}^{-1} \cdot \mathrm{K}^{-1}\right)$ \\
\hline 298 & $(5.12 \pm 0.39) \times 10^{4}$ & $0.999 \pm 0.009$ & $-26.83 \pm 0.22$ & $78.33 \pm 5.86$ & $352.92 \pm 18.88$ \\
303 & $(8.31 \pm 0.66) \times 10^{4}$ & $1.065 \pm 0.007$ & $-28.59 \pm 0.13$ & & \\
310 & $(1.73 \pm 0.29) \times 10^{5}$ & $1.155 \pm 0.002$ & $-31.07 \pm 0.01$ & & \\
\hline
\end{tabular}

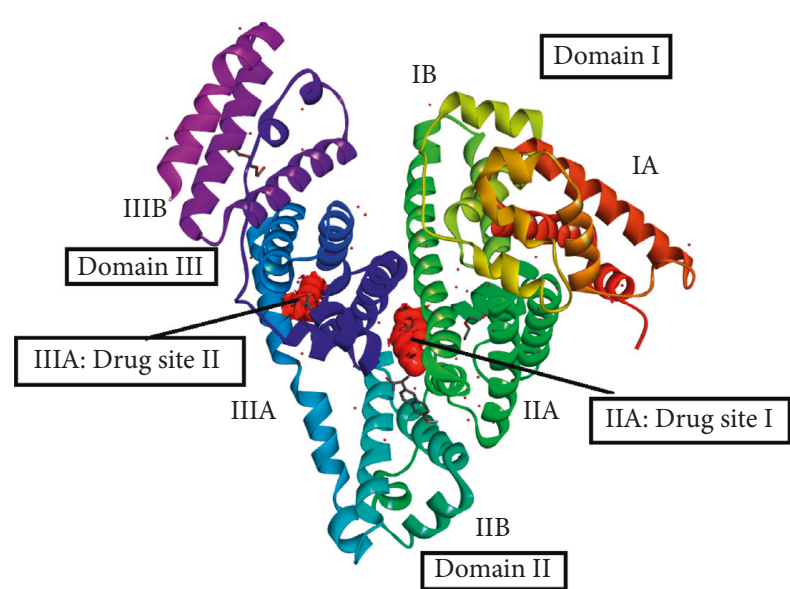

FIgURE 4: Structure of BSA with the binding sites I and II (subdomains IIA and IIIA).

TABLE 3: Binding constant of $5 \mathrm{~d}$ in presence of site specific markers phenylbutazone (PBT) and ibuprofen (IBF).

\begin{tabular}{ccccc}
\hline & $T(\mathrm{~K})$ & {$[\mathbf{5 d}]$} & {$[\mathbf{5 d} / \mathrm{PBT}]$} & {$[\mathbf{5 d} / \mathrm{IBF}]$} \\
\hline$K_{\mathrm{b}}$ & 298 & $5.40 \times 10^{4}$ & $0.10 \times 10^{2}$ & $0.39 \times 10^{3}$ \\
\hline
\end{tabular}

parameters are calculated from the Van't Hoff equation (Figure 3(c)):

$$
\ln K_{\mathrm{b}}=-\frac{\Delta H^{\circ}}{R T}+\frac{\Delta S^{\circ}}{R},
$$

where $K_{\mathrm{b}}$ and $R$ represent the binding and the gas constant, respectively. The $\Delta H^{\circ}$ and $\Delta S^{\circ}$ are the enthalpy and entropy change, respectively; $\Delta G^{\circ}$ represents Gibbs free energy. The calculated values of these parameters are given in Table 2. The value of $\Delta H^{\circ}>0$ and $\Delta S^{\circ}>0$ suggests a hydrophobic interaction. The van der Waals force or hydrogen bond formation is implied if $\Delta H^{\circ}<0$ and $\Delta S^{\circ}<0$, whereas $\Delta H^{\circ} \approx 0$ and $\Delta S^{\circ}>0$ indicate an electrostatic force. The results (negative $\Delta G^{\circ}$ ) clearly indicate a spontaneous binding interaction between $\mathbf{5 d}$ and BSA. The positive $\Delta H^{\circ}$ and $\Delta S^{\circ}$ infer major influence of hydrophobic forces in the interaction of BSA with $\mathbf{5 d}$.

3.4. UV-Vis Spectroscopy. UV-Vis spectroscopy is widely applied for investigating protein-ligand interaction and structural changes that might have occurred because of it [36-38]. The protein molecules present in the complex absorb light at $\lambda_{\max }=280 \mathrm{~nm}$, primarily due to amino acid residues Phe, Trp, and Tyr present in BSA, and the other absorption peak in BSA occurs at $205 \mathrm{~nm}$ and is attributed to the polypeptide backbone of BSA.

The microenvironmental alterations within the vicinity of amino acids due to protein-ligand interaction provide information regarding the binding mechanism [39, 40]. An increase in the absorbance of BSA was observed at $280 \mathrm{~nm}$ and $205 \mathrm{~nm}$ [41]. This increase was attributed to the interaction of $\mathbf{5 d}$ and BSA, and the maximum absorbance shifted $(1 \mathrm{~nm})$ towards a higher wavelength (Figure 5(a)) at both the studied wavelengths. These shifts at $280 \mathrm{~nm}$ and at $205 \mathrm{~nm}$ suggest change in the microenvironment of tyrosine and peptide bonds in the protein. Thus, collective shifts at $205 \mathrm{~nm}$ and $280 \mathrm{~nm}$ suggest conformational changes in the protein structure [42]. A plot between the mixture of BSA and $\mathbf{5 d}$ versus concentration of $\mathbf{5 d}$ at 205 and $280 \mathrm{~nm}$ revealed that the plots obtained were nonlinear and deviated from the straight line (Figure 5(c)). This behavior of UV data suggests complex formation conformational changes in the BSA on its interaction with 5d. The normalized fluorescence excitation spectra (normalized for quenching effect) were also obtained for BSA and 5d mixtures and are given in Figure 5(d). After normalization, no change in excitation spectra were observed at $\sim 280 \mathrm{~nm}$; however, the peak at $\sim 226 \mathrm{~nm}$ which represents the lowest excited state of aromatic amino acids (Trp and Tyr) of BSA showed a decrease in the intensity upon addition of $\mathbf{5 d}$ and suggests microenvironmental changes in the vicinity of Trp and Tyr residues. The involvement of dynamic quenching in the interaction of BSA and $\mathbf{5 d}$ was not considered as the absorption spectrum of BSA in presence of $\mathbf{5} \mathbf{d}$ might have been unaffected in this case. However, an increase in the absorption intensity of BSA on its interaction with $\mathbf{5 d}$ suggests complex formation between them (Figure 5(b)) and involvement of static quenching [43]. Moreover, the no-overlap was observed in the absorption spectra of BSA, 5d, BSA-5d, and (BSA-5d)-5d. These results in Figure 5(b) also confirm that complex formation took place between BSA and $\mathbf{5 d}$.

3.5. Energy Transfer. The binding distance in BSA and 5d was calculated using fluorescence resonance energy transfer 

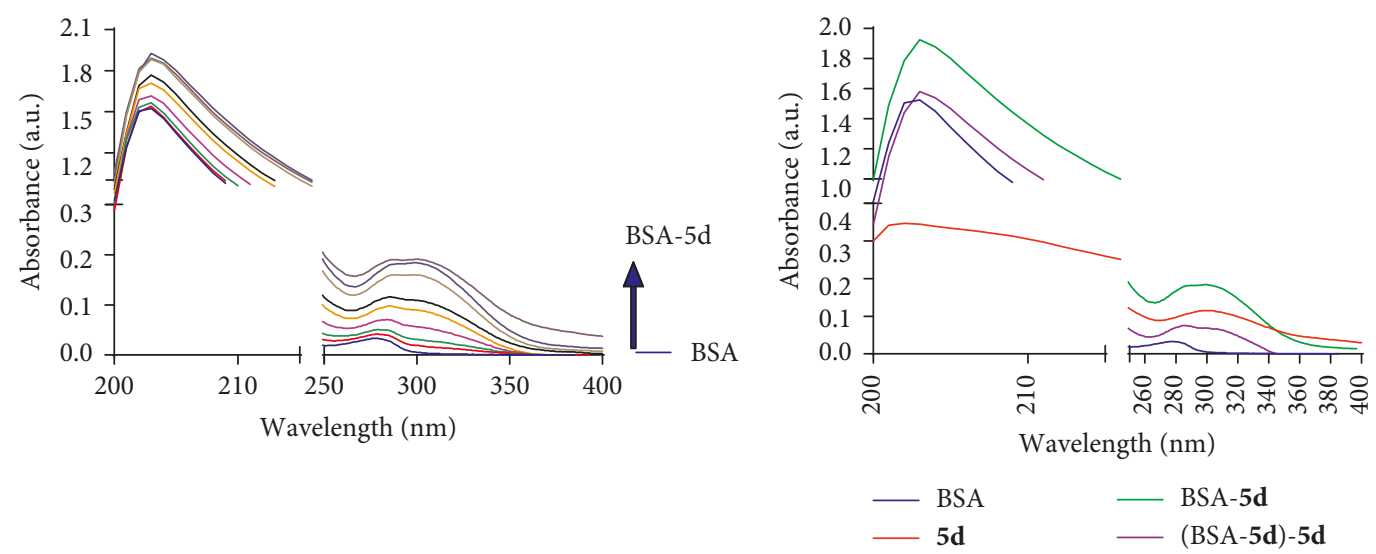

(a)
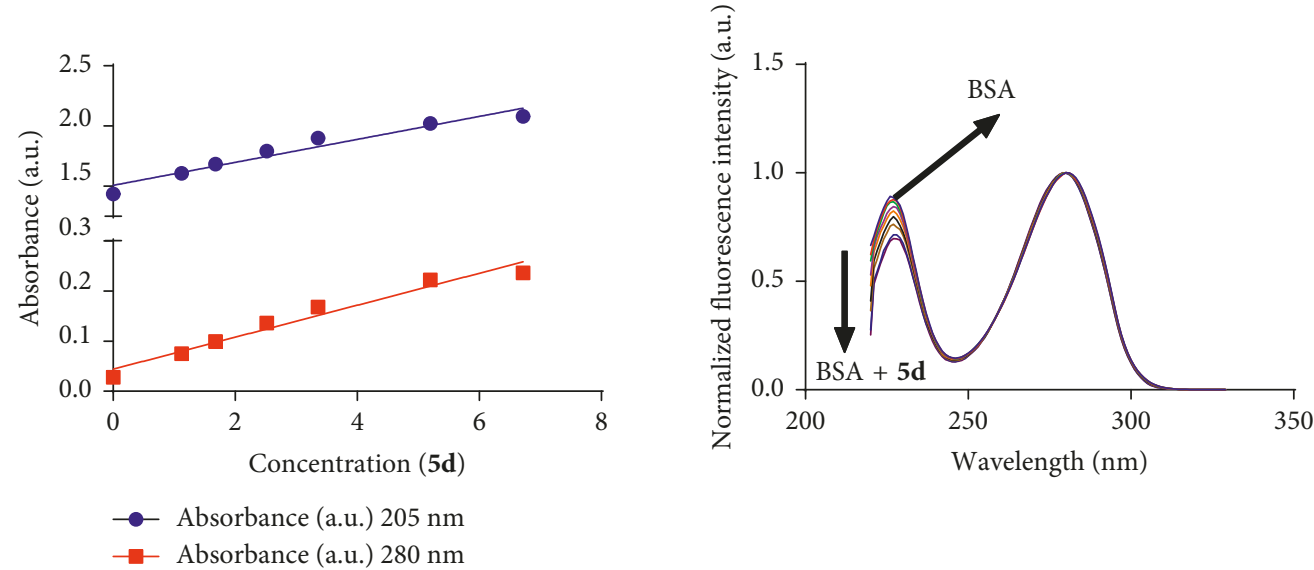

(c)

(d)

FigURE 5: (a) UV absorbance spectra of BSA $(1.5 \mu \mathrm{M})$ in presence of $\mathbf{5 d}$ concentrations $(0-18 \mu \mathrm{M})$ at $205 \mathrm{~nm}$ and $280 \mathrm{~nm}$. (b) The absorption spectrum of BSA $(1.5 \mu \mathrm{M})$ and $\mathbf{5 d}(13.5 \mu \mathrm{M})$ alone and the spectra of their BSA-5d complex and absorbance of (BSA-5d complex-5d). (c) Plot of the absorbance of the mixture, at 205 and $280 \mathrm{~nm}$, versus the concentration of $\mathbf{5 d}$. (d) Excitation spectra of BSA (1.5 $\mu \mathrm{M})$ in presence of $\mathbf{5 d}$ $(0-18 \mu \mathrm{M})$.

(FRET) [34, 35] (Figure 6). FRET occurs due to an overlap in the emission spectrum (donor) and absorption spectrum (acceptor). The FRET efficiency is dependent on the degree of overlap and distance between the emission and absorption spectrum and is calculated as [44]

$$
E=1-\frac{F_{0}}{F}=\frac{R_{0}^{6}}{R_{0}^{6}+r^{6}}
$$

where energy transfer efficiency is given as $E$. " $r$ " is the donor and acceptor distance, and $R_{0}$ is the critical binding distance when energy transfers $(50 \%)$ and is represented by

$$
R_{0}^{6}=8.79 \times 10^{-25} K^{2} \phi_{D} n^{-4} J,
$$

where $K^{2}$ denotes the dipole orientation; medium refractive index is given as " $n$ "; " $\phi$ " is the donor's quantum yield in absence of acceptor; and $J$ denotes the spectral overlap extent in emission and absorption spectra and is given as

$$
J(\lambda)=\frac{\sum F(\lambda) \varepsilon(\lambda) \lambda^{4} \Delta \lambda}{\sum(\lambda) \Delta \lambda},
$$

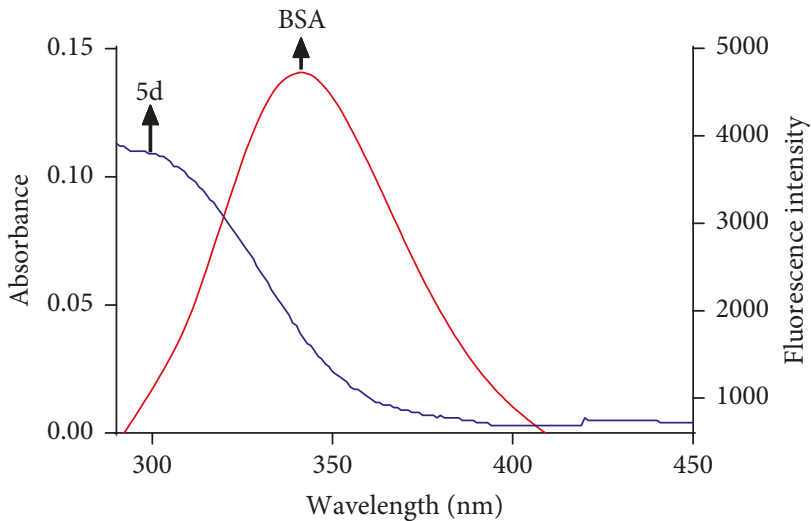

FIgURE 6: Spectral overlap of donor BSA $(1.5 \mu \mathrm{M})$ (fluorescence spectrum) with acceptor $5 \mathbf{d}(1.5 \mu \mathrm{M})$ (absorption spectrum).

where $F(\lambda)$ is the emission spectrum fluorescent donor. $\epsilon(\lambda)$ denotes molar absorptivity coefficient of acceptor. The value for $K^{2}=2 / 3$ (random orientation of fluid solution). The 
refractive index of the medium was taken as 1.336 and $\phi_{\mathrm{D}}=0.118$ for BSA $[43,44]$. The calculated values for $E, R_{0}$, and $J(\lambda)$ are presented in Table 4.

The binding distance $r=3.89$ infers close proximity of the donor and acceptor to one another. Further, the distance amongst donor and acceptor $(r<8 \mathrm{~nm})$ suggests a high possibility of nonradiative energy transfer from BSA to $\mathbf{5 d}$. In addition, static fluorescence quenching mechanism can also be inferred between BSA and $\mathbf{5 d}$.

\section{Conformational Studies}

4.1. Synchronous Fluorescence Studies. Synchronous fluorescence studies provide information regarding the microenvironmental changes in the amino acids responsible for fluorescence of protein [44-47]. These studies measure the shift in the $\lambda_{\text {em, }}$ which might have occurred due to variations near the chromophores of a molecule. The fluorescent residues Trp and Tyr of BSA can be analyzed for any changes in their microenvironment at $\Delta \lambda=15$ and $60 \mathrm{~nm}$, respectively. The polarity near the chromophore molecule relates to the shift in the emission of maximum intensity. The shift in the position of fluorescence emission maximum corresponds to changes of the polarity around the chromophore molecule. Therefore, a blue shift in the maximum emission suggests a more hydrophobic microenvironment for amino acid residues, and a red shift infers a polar environment for them and more solvent exposure.

No shift in the spectrum at $\Delta \lambda=15 \mathrm{~nm}$ suggests insignificant effect of $\mathbf{5 d}$ on the Tyr microenvironment (Figure $7(\mathrm{a})$ ). Moreover, insignificant red shift $(1 \mathrm{~nm})$ was also observed at $\Delta \lambda=60 \mathrm{~nm}$ was observed (Figure $7(\mathrm{~b})$ ). These nonsignificant shifts in the emission wavelengths suggest that $\mathbf{5 d}$ interaction with BSA has no affect over the conformation of the regions where Tyr and Trp are located [42].

4.2. Three-Dimensional Fluorescence Spectroscopy. The 3D fluorescence spectroscopy has gained quite popularity to access the protein structural changes. It gives a detailed account of the conformation modifications in protein due to protein-ligand interaction [21, 43]. The changes in the conformation and the microenvironment of BSA are explored by relating the changes in the spectrum of BSA in absence and after addition of 5d (Figure 7). The identified peaks (Figure $8(\mathrm{a})$ and $8(\mathrm{~b})$ ) were as follows: peak a (Rayleigh scattering peak; $\left.\lambda_{\mathrm{ex}}=\lambda_{\mathrm{em}}\right)$ and peak $b\left(2^{\text {nd }}\right.$ order scattering peak; $\lambda_{\mathrm{em}}=2 \mathrm{ex}$ ) [46]. The intensity of peak a increased with the increasing concentration of $\mathbf{5 d}$. The increased peak intensity is attributed to complex formation, and thus, a bigger macromolecule size leads to higher scattering effect. Peak $1\left(\lambda_{\mathrm{ex}} / \lambda_{\mathrm{em}}=278 / 340 \mathrm{~nm}\right)$ represents the Trp and Tyr residues, and both are excited at $\sim 280 \mathrm{~nm}$ and are responsible for the fluorescence of BSA. The fluorescence of Phe is negligible and is not taken into account. Peak $2\left(\lambda_{\mathrm{ex}} / \lambda_{\mathrm{em}}=226 / 340 \mathrm{~nm}\right)$ represents the fluorescence from the excited electronic states of Trp and Tyr residues present in BSA. The 3D-contour plots for fluorescence
TABLE 4: BSA-5d energy transfer parameters at equimolar concentration $\left(6.7 \times 10^{-6} \mathrm{M}\right)$ of BSA and $\mathbf{5 d}$.

\begin{tabular}{ccccc}
\hline & $J\left(\mathrm{~cm}^{3} \cdot \mathrm{mol}^{-1}\right)$ & $E$ & $R_{0}(\mathrm{~nm})$ & $r(\mathrm{~nm})$ \\
\hline BSA-5d system & $3.77 \times 10^{-15}$ & 0.0356 & 2.23 & 3.89 \\
\hline
\end{tabular}

studies are presented in Figures 8(c) and 8(d). The ratio of intensities of peak 1 for the BSA: BSA-5d system was $1: 0.77$ and of peak 2 was 1:0.69 (Figure 8). Both the peaks are from different residues in BSA, and alterations in the FI upon interaction with $\mathbf{5 d}$ suggest some sort of microenvironmental changes in the BSA. Peak 2 which was believed to be from the peptide backbone has been proved wrong [48]. Peak 2 is due to the aromatic residues that get absorbed in the far UV-region, swiftly relax to the lowest excited state, and then emit in the range $300-350 \mathrm{~nm}$. Therefore, Peak 2 also provides information about the microenvironmental changes that might have occurred during the Trp and Tyr residues as in case of excitation at $\sim 280 \mathrm{~nm}$. The synchronous fluorescence results indicated no change in the protein conformation near Trp and Tyr residues. However, the excitation spectra in Figure 5(d) showed changes in the excitation of BSA upon addition of 5d. Figure 9 represents the Tyr and Trp residues corresponding to $\Delta \lambda=15$ and $60 \mathrm{~nm}$, respectively, and 3D contour plot of fluorescence. The figure confirms that the value for $\Delta \lambda=60 \mathrm{~nm}$ leads to direct probe of tryptophan emission.

4.3. Molecular Docking. Molecular docking helps to understand and interpret the interaction mechanism between BSA and 5d [47, 49, 50]. Molecular docking acts as an insilico tool to analyze the protein-ligand interaction and authenticate experimental interpretations. As is already known, the hydrophobic cavities of BSA in subdomains IIA and IIIA represent sites I and II, respectively. The site probe displacement studies suggested subdomain IIA/IIIA or both of BSA were involved in binding to $\mathbf{5 d}$. The conformations which had least binding energy for site I and site II are given in Figure 10. The ligand 5d embedded in the hydrophobic cavity of subdomains IIA and IIIA with a free binding energy of $-31.04 \mathrm{~kJ} \cdot \mathrm{mol}^{-1}$ and $-30.12 \mathrm{~kJ} \cdot \mathrm{mol}^{-1}$. The ligand $\mathbf{5 d}$ is surrounded by the amino acid residues Ser 343, Ser 201, Ser 453, Arg 217, Arg 198, Arg 194, Leu 454, Leu 480, Leu 346, Leu 210, Leu 197, Ala 290, Ala 209, Val 342, Val 481, Tyr 451, and Asp 450 in the hydrophobic cavity of IIA (Figures 10(a) and $10(\mathrm{c})$ ). Tryptophan residue Trp 213 was also found in close vicinity of $\mathbf{5 d}$ at site $\mathrm{I}$. Further, one hydrogen bond with Arg 194 (N-Arg194, $2.88 \AA$ ) was observed. The hydrophobic residues involved in the interaction were Ala 290, Val 342, Leu 197, Leu 454, Leu 346, Leu 480, and Ala 209.

Similarly, the hydrophobic cavity of subdomain IIIA has Asn 390, Ser 488, Lys 413, Arg 409, Gln 389, Leu 386, Leu 490, Leu 429, Leu 456, Leu 452, Thr 448, Val 432, Phe 487, and Phe 402, surrounding residues IIA (Figures 10(b) and 10(d)). Tyrosine residue (Tyr 410) was found in the vicinity of $5 \mathrm{~d}$ site II, and a hydrogen bond was found between $5 \mathrm{~d}$ and Tyr 410 (N-Tyr410, $2.35 \AA$ ). Another hydrogen bond was found with Lys $413(\mathrm{~N}-\mathrm{Lys} 413,3.15 \AA$ ). The hydrophobic 


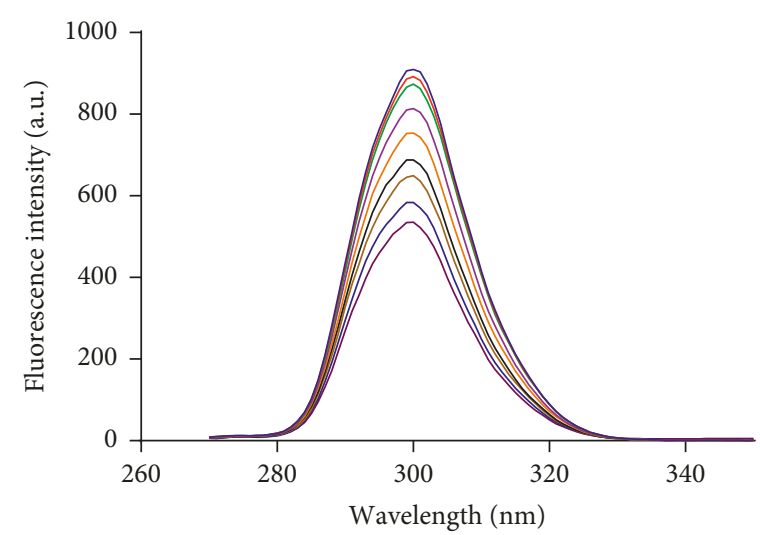

(a)

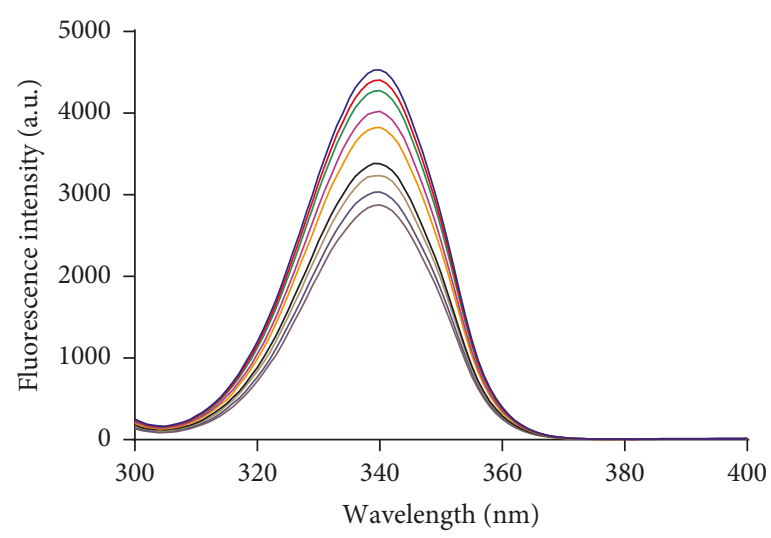

(b)

FIGURE 7: Synchronous fluorescence spectroscopic data of BSA $(1.5 \mu \mathrm{M})$ in presence of $5 \mathbf{d}(0-18 \mu \mathrm{M})$ at $298 \mathrm{~K}$ (a) $\Delta \lambda=15 \mathrm{~nm}$ and (b) $\Delta \lambda=60 \mathrm{~nm}$.

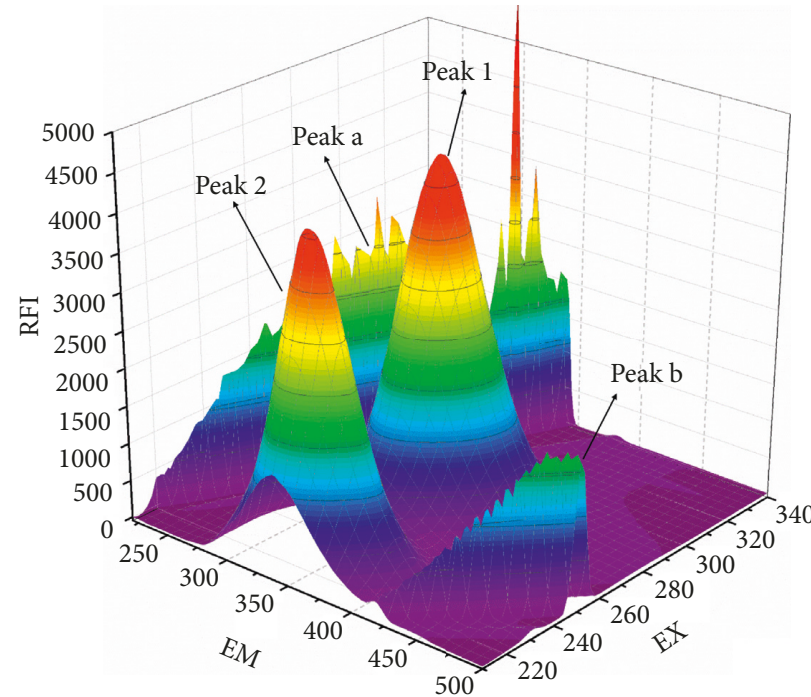

(a)

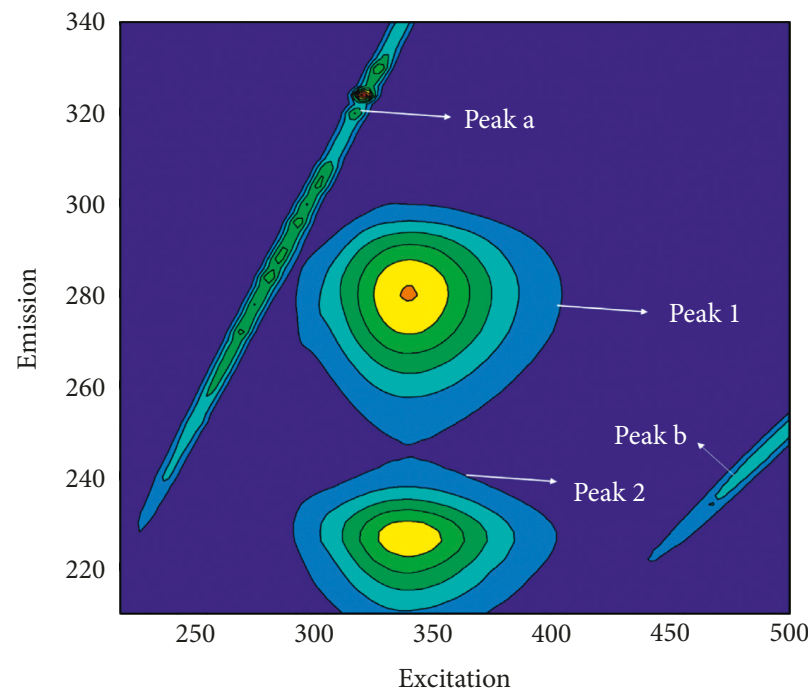

(c)

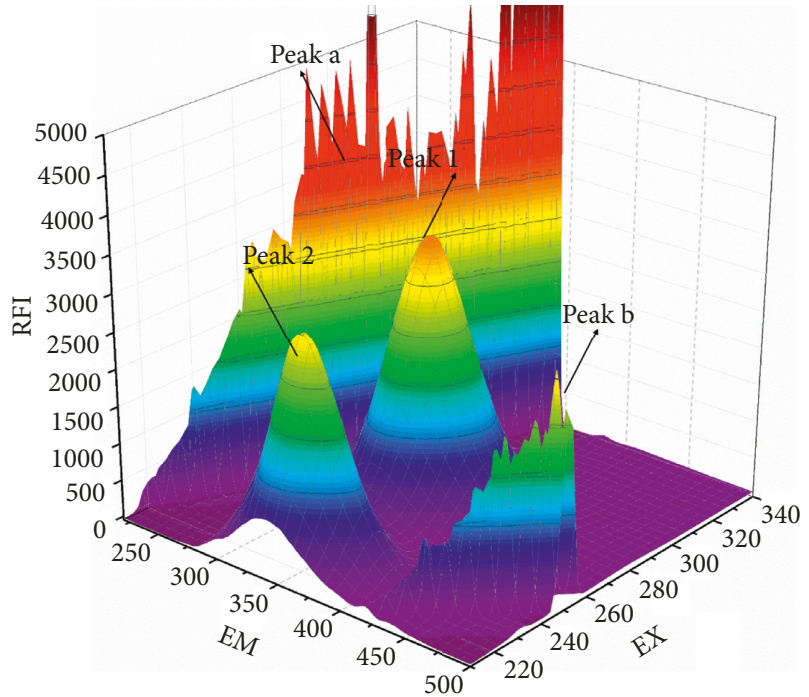

(b)

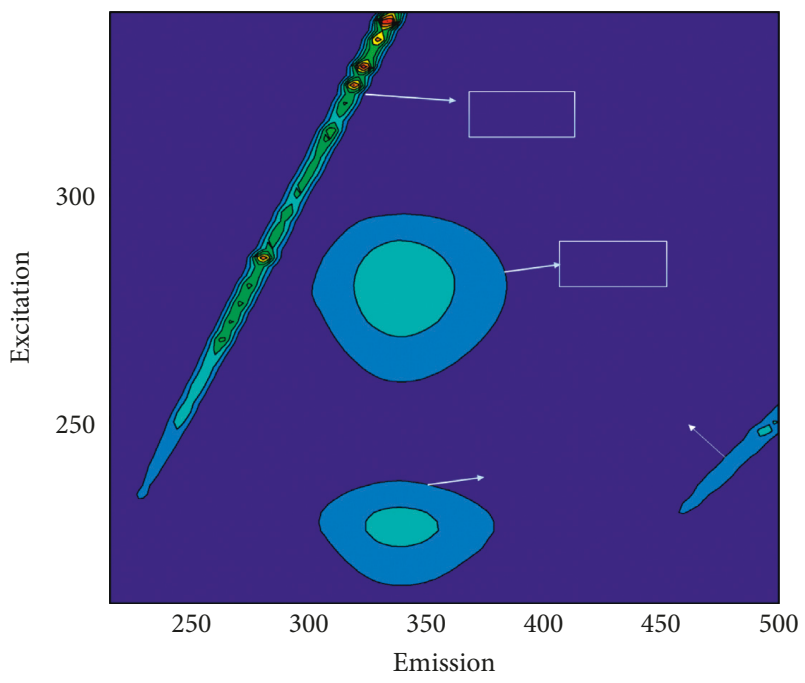

(d)

Figure 8: Three-dimensional fluorescence analysis of BSA $(1.5 \mu \mathrm{M})(\mathrm{a}, \mathrm{c})$ and BSA $(1.5 \mu \mathrm{M})-5 \mathrm{~d}(6.5 \mu \mathrm{M})$ system (b, d). 


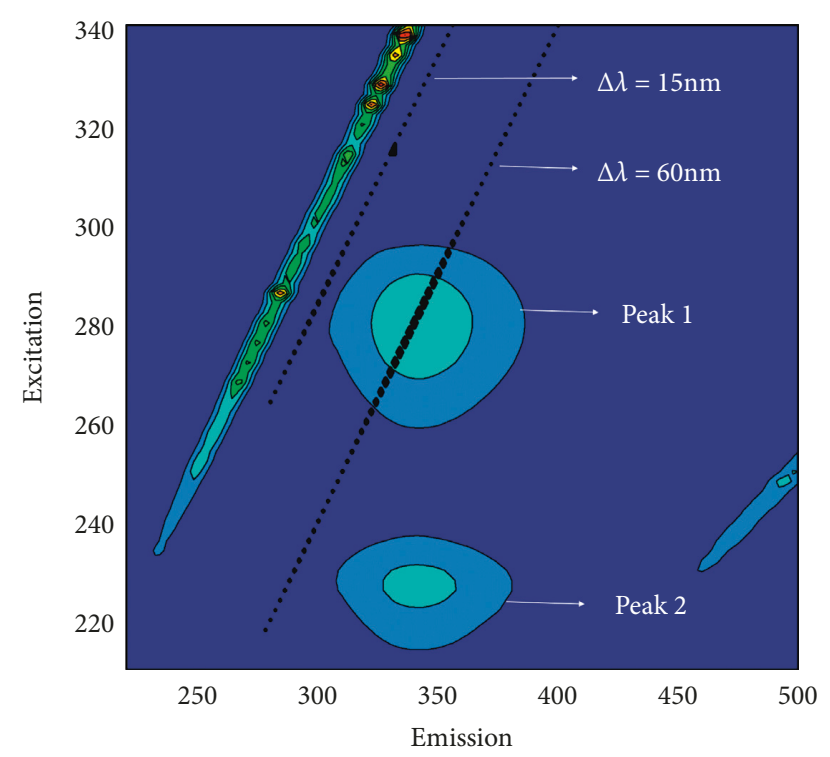

FIGURE 9: Relation between the synchronous fluorescence spectroscopy and three-dimensional data of BSA and 5d.

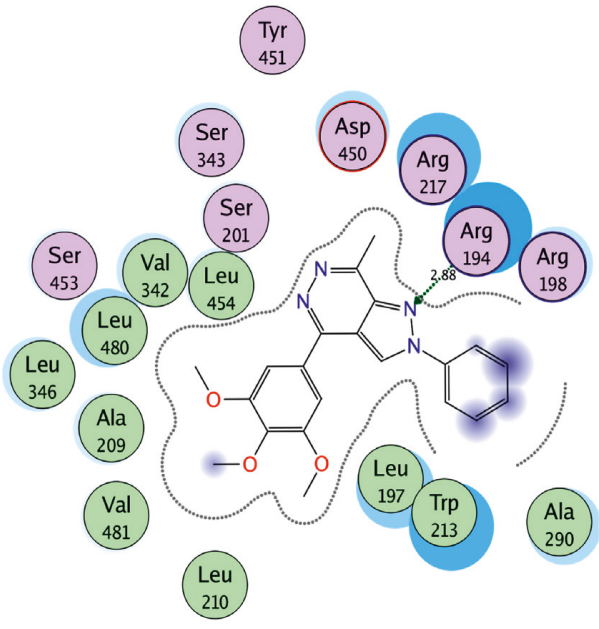

(a)

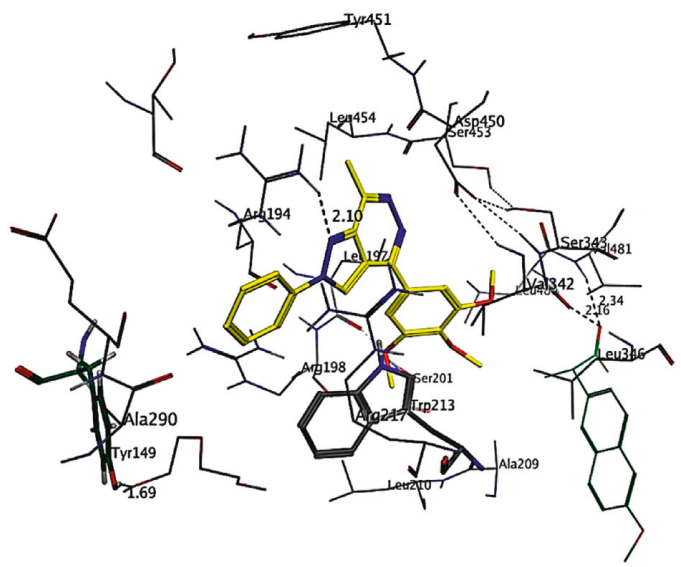

(c)

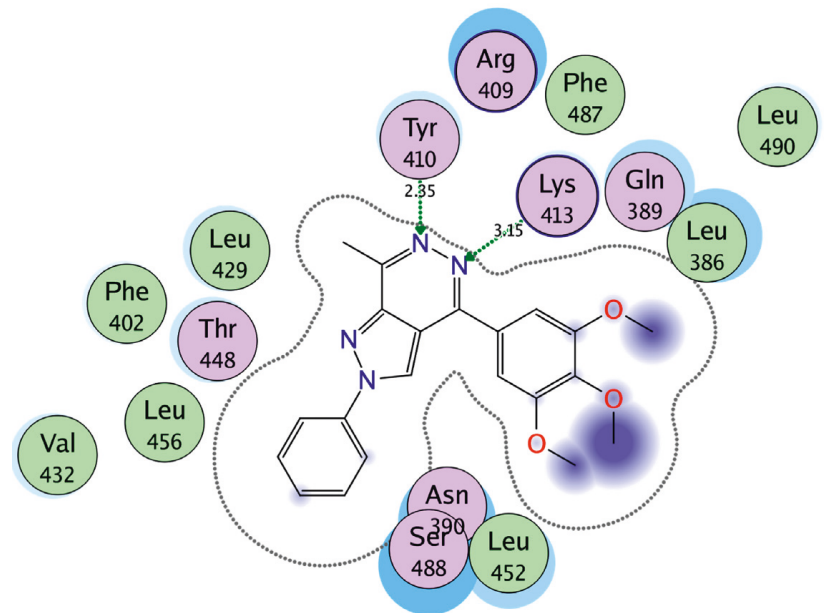

(b)

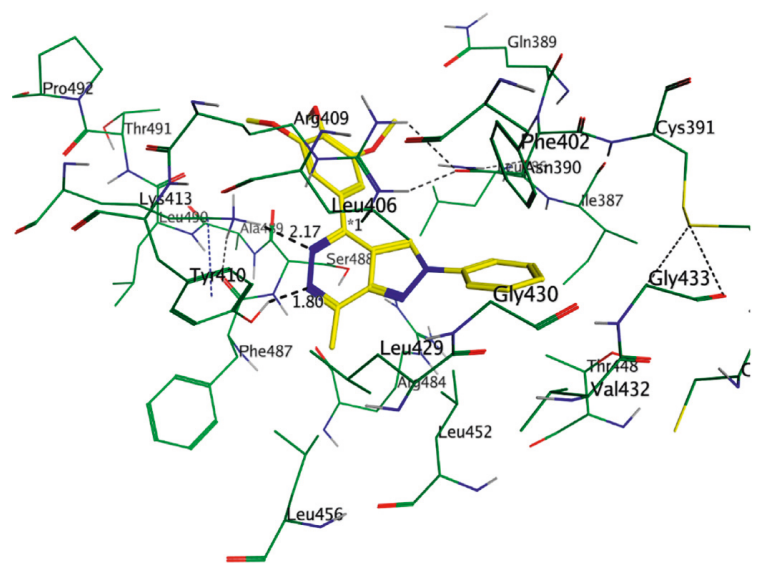

(d)

FIGURE 10: Two- and three-dimensional view of (a) the amino acid residues surrounding $\mathbf{5 d}$ at site I; (b) the amino acid residues surrounding $\mathbf{5 d}$ at site II; (c) the docking conformation of 5d-BSA system with lowest energy at site I; and (d) docking conformation of 5d-BSA system with lowest energy at site II. 
residues in the vicinity of the site II were Leu 386, Leu 452, and Gln 389 [51, 52].

These results are in confirmation of the thermodynamic studies and site probe studies where it was inferred that hydrophobic forces contributed in the BSA-5d interaction as well as both sites I and II were also involved. The rigid and flexible docking were performed for the site I of BSA. In both the flexible and rigid docking, only one hydrogen bond was found with slight difference in the bond length between Arg 194 and 5d in the flexible (3.12 $\AA$ ) and rigid $(2.88 \AA)$ docking. The amino acid residue His 241 contains an imidazole ring and can quench the Trp 213 fluorescence. The distance between His 241 and $\operatorname{Trp} 213$ is $3.9 \AA$ in the rigid docking, and when compared to the flexible docking, the distance was reduced to $3.7 \AA$. Since His 241 is placed closer to the Trp 213 residue, influence of His 241 on $\operatorname{Trp}$ 213 cannot be ruled out. Further, the distances between Trp-213 and 5d were $3.3 \AA$ in the rigid and $3.5 \AA$ in the flexible docking studies, and these results were consistent with the results of the fluorescence studies, where no significant shift was observed on interaction between BSA and 5d [53].

\section{Conclusion}

The study presents the binding interaction between BSA and 5d using different spectrometric and molecular docking techniques. The BSA-5d interaction followed a static quenching mechanism. The binding sites, site I and/or site II of BSA, participated in the interaction with $\mathbf{5 d}$. The site probe and molecular docking study results corroborated one another. Three-dimensional fluorescence and UVspectrophotometric studies indicated conformational changes in BSA due to its interaction with 5d. Positive enthalpy and entropy of the BSA-5d system suggested hydrophobic interaction. The present study can be useful to understand pharmacological and biochemical behavior of 5d since strong or weak binding to these proteins plays a major rule in the therapeutic capability of drugs. Binding of the drug to serum albumin also influences their distribution and elimination, and $\mathbf{5 d}$ has a moderate binding affinity to BSA.

\section{Data Availability}

The data used to support the findings of this study are available from the corresponding author upon request.

\section{Conflicts of Interest}

The authors declare that they have no conflicts of interest.

\section{Acknowledgments}

The authors would like to extend their sincere appreciation to the Deanship of Scientific Research. This work was supported by the Deanship of Scientific Research, King Saud University (research group no. RG-1435-073).

\section{References}

[1] J.-Y. Jouzeau, B. Terlain, A. Abid, E. Nédélec, and P. Netter, "Cyclo-oxygenase isoenzymes," Drugs, vol. 53, no. 4, pp. 563-582, 1997.

[2] J. A. Cairns, "The coxibs and traditional nonsteroidal antiinflammatory drugs: a current perspective on cardiovascular risks," Canadian Journal of Cardiology, vol. 23, no. 2, pp. 125-131, 2007.

[3] L. P. Lipsky, S. B. Abramson, L. Crofford, R. N. Dubois, L. S. Simon, and L. B van de Putte, "The classification of cyclooxygenase inhibitors," Journal of rheumatology, vol. 25, no. 12, pp. 2298-303, 1998.

[4] C. Michaux and C. Charlier, "Structural approach for COX-2 inhibition," Mini-Reviews in Medicinal Chemistry, vol. 4, no. 6, pp. 603-615, 2004

[5] F. E. Silverstein, G. Faich, J. L. Goldstein et al., "Gastrointestinal toxicity with celecoxib vs nonsteroidal antiinflammatory drugs for osteoarthritis and rheumatoid arthritis," JAMA, vol. 284, no. 10, pp. 1247-1255, 2000.

[6] B. M. Psaty and C. D. Furberg, "COX-2 inhibitors-lessons in drug safety," New England journal of medicine, vol. 352, no. 11, pp. 1133-1135, 2005.

[7] C. D. Funk and G. A. FitzGerald, "COX-2 inhibitors and cardiovascular risk," Journal of Cardiovascular Pharmacology, vol. 50, no. 5, pp. 470-479, 2007.

[8] M. V. Patel, R. Bell, S. Majest, R. Henry, and T. Kolasa, "Synthesis of 4,5-diaryl-1H-pyrazole-3-ol derivatives as potential COX-2 inhibitors," Journal of Organic Chemistry, vol. 69, no. 21, pp. 7058-7065, 2004.

[9] A. K. Tewari, P. Srivastava, V. P. Singh, A. Singh, R. K. Goel, and C. G. Mohan, "Novel anti-inflammatory agents based on pyrazole based dimeric compounds; design, synthesis, docking and in vivo activity," Chemical and Pharmaceutical Bulletin, vol. 58, no. 5, pp. 634-638, 2010.

[10] P. K. Sharma, S. Kumar, P. Kumar et al., "Synthesis and biological evaluation of some pyrazolylpyrazolines as antiinflammatory-antimicrobial agents," European journal of medicinal chemistry, vol. 45, no. 6, pp. 2650-2655, 2010.

[11] S. El-Hawash and A. El-Mallah, "Synthesis of some novel pyrazole derivatives as potential antiinflammatory agents with minimum ulcerogenic activity," Die Pharmazie, vol. 53, no. 6, pp. 368-373, 1998.

[12] N. Gökhan-Kelekçi, S. Yabanoğlu, E. Küpeli et al., "A new therapeutic approach in Alzheimer disease: some novel pyrazole derivatives as dual MAO-B inhibitors and antiinflammatory analgesics," Bioorganic and Medicinal Chemistry, vol. 15, no. 17, pp. 5775-5786, 2007.

[13] A. Hall, A. Billinton, S. H. Brown et al., "Non-acidic pyrazole EP1 receptor antagonists with in vivo analgesic efficacy," Bioorganic and Medicinal Chemistry Letters, vol. 18, no. 11, pp. 3392-3399, 2008.

[14] R. L. Jayaraj, K. Tamilselvam, T. Manivasagam, and N. Elangovan, "Neuroprotective effect of CNB-001, a novel pyrazole derivative of curcumin on biochemical and apoptotic markers against rotenone-induced SK-N-SH cellular Model of Parkinson's disease," Journal of Molecular Neuroscience, vol. 51, no. 3, pp. 863-870, 2013.

[15] Z. Özdemir, H. B. Kandilci, B. Gümüşel, Ü. Çalış, and A. A. Bilgin, "Synthesis and studies on antidepressant and anticonvulsant activities of some 3-(2-furyl)-pyrazoline derivatives," European Journal of Medicinal Chemistry, vol. 42, no. 3, pp. 373-379, 2007. 
[16] M. Abdel-Aziz, G. E.-D. A. Abuo-Rahma, and A. A. Hassan, "Synthesis of novel pyrazole derivatives and evaluation of their antidepressant and anticonvulsant activities," European journal of medicinal chemistry, vol. 44, no. 9, pp. 3480-3487, 2009.

[17] M. A. Bhat, A. F. Ahmed, Z.-H. Wen, M. A. Al-Omar, and H. A. Abdel-Aziz, "Synthesis, anti-inflammatory and neuroprotective activity of pyrazole and pyrazolo[3,4-d] pyridazine bearing 3,4,5-trimethoxyphenyl," Medicinal Chemistry Research, vol. 26, no. 7, pp. 1557-1566, 2017.

[18] T. A. Wani, A. H. Bakheit, M. N. Ansari, A.-R. Al-Majed, B. M. AlQahtani, and S. Zargar, "Spectroscopic and molecular modeling studies of binding interaction between bovine serum albumin and roflumilast," Drug Design, Development and Therapy, vol. 12, pp. 2627-2634, 2018.

[19] D. Li, "Studies on the interaction of cefepime hydrochloride with bovine serum albumin by fluorescence, synchronous fluorescence, three-dimensional fluorescence and circular dichroism," Journal of Bioanalysis and Biomedicine, vol. 9, pp. 107-113, 2017.

[20] Y. Teng, X. Wang, L. Zou, M. Huang, and X. Du, "Experimental and theoretical study on the binding of 2-mercaptothiazoline to bovine serum albumin," Journal of Luminescence, vol. 161, pp. 14-19, 2015.

[21] T. A. Wani, A. H. Bakheit, M. Abounassif, and S. Zargar, "Study of interactions of an anticancer drug neratinib with bovine serum albumin: spectroscopic and molecular docking approach," Frontiers in Chemistry, vol. 6, p. 47, 2018.

[22] M. Makarska-Bialokoz, "Investigation of the binding affinity in vitamin B12-Bovine serum albumin system using various spectroscopic methods," Spectrochimica Acta Part A: Molecular and Biomolecular Spectroscopy, vol. 184, pp. 262-269, 2017.

[23] M. Makarska-Bialokoz, "Interactions of hemin with bovine serum albumin and human hemoglobin: a fluorescence quenching study," Spectrochimica Acta Part A: Molecular and Biomolecular Spectroscopy, vol. 193, pp. 23-32, 2018.

[24] S. Evoli, D. L. Mobley, R. Guzzi, and B. Rizzuti, "Multiple binding modes of ibuprofen in human serum albumin identified by absolute binding free energy calculations," Physical Chemistry Chemical Physics, vol. 18, no. 47, pp. 32358-32368, 2016.

[25] E. Żurawska-Płaksej, A. Rorbach-Dolata, K. Wiglusz, and A. Piwowar, "The effect of glycation on bovine serum albumin conformation and ligand binding properties with regard to gliclazide," Spectrochimica Acta Part A: Molecular and Biomolecular Spectroscopy, vol. 189, pp. 625-633, 2018.

[26] T. Topală, A. Bodoki, L. Oprean, and R. Oprean, "Bovine serum albumin interactions with metal complexes," Clujul Medical, vol. 87, no. 4, p. 215, 2014.

[27] A. Ghisaidoobe and S. Chung, "Intrinsic tryptophan fluorescence in the detection and analysis of proteins: a focus on förster resonance energy transfer techniques," International Journal of Molecular Sciences, vol. 15, no. 12, pp. 22518-22538, 2014.

[28] A. Varlan and M. Hillebrand, "Bovine and human serum albumin interactions with 3-carboxyphenoxathiin studied by fluorescence and circular dichroism spectroscopy," Molecules, vol. 15, no. 6, pp. 3905-3919, 2010.

[29] G. Paramaguru, A. Kathiravan, S. Selvaraj, P. Venuvanalingam, and R. Renganathan, "Interaction of anthraquinone dyes with lysozyme: evidences from spectroscopic and docking studies," Journal of hazardous materials, vol. 175, no. 1-3, pp. 985-991, 2010.
[30] W. R. Ware, "Oxygen quenching of fluorescence in solution: an experimental study of the diffusion process," Journal of Physical Chemistry, vol. 66, no. 3, pp. 455-458, 1962.

[31] F.-L. Cui, J. Fan, J.-P. Li, and Z.-D. Hu, "Interactions between 1-benzoyl-4-p-chlorophenyl thiosemicarbazide and serum albumin: investigation by fluorescence spectroscopy," Bioorganic and Medicinal Chemistry, vol. 12, no. 1, pp. 151-157, 2004.

[32] A. Usman and M. Ahmad, "Binding of Bisphenol-F, a bisphenol analogue, to calf thymus DNA by multispectroscopic and molecular docking studies," Chemosphere, vol. 181, pp. 536-543, 2017.

[33] A. Ababou and J. E. Ladbury, "Survey of the year 2004: literature on applications of isothermal titration calorimetry," Journal of Molecular Recognition, vol. 19, no. 1, pp. 79-89, 2006.

[34] M. Y. Losytskyy, V. B. Kovalska, O. A. Varzatskii et al., "An interaction of the functionalized closo -borates with albumins: the protein fluorescence quenching and calorimetry study," Journal of Luminescence, vol. 169, pp. 51-60, 2016.

[35] G. A. Siddiqui, M. K. Siddiqi, R. H. Khan, and A. Naeem, "Probing the binding of phenolic aldehyde vanillin with bovine serum albumin: evidence from spectroscopic and docking approach," Spectrochimica Acta Part A: Molecular and Biomolecular Spectroscopy, vol. 203, pp. 40-47, 2018.

[36] M. D. Meti, S. T. Nandibewoor, S. D. Joshi, U. A. More, and S. A. Chimatadar, "Multi-spectroscopic investigation of the binding interaction of fosfomycin with bovine serum albumin," Journal of Pharmaceutical Analysis, vol. 5, no. 4, pp. 249-255, 2015.

[37] T. A. Wani, A. H. Bakheit, S. Zargar, M. A. Hamidaddin, and I. A. Darwish, "Spectrophotometric and molecular modelling studies on in vitro interaction of tyrosine kinase inhibitor linifanib with bovine serum albumin," PLoS One, vol. 12, no. 4, Article ID e0176015, 2017.

[38] A. S. Abdelhameed, S. Nusrat, M. R. Ajmal, S. M. Zakariya, M. Zaman, and R. H. Khan, "A biophysical and computational study unraveling the molecular interaction mechanism of a new Janus kinase inhibitor Tofacitinib with bovine serum albumin," Journal of Molecular Recognition: JMR, vol. 30, no. 6, 2017.

[39] A. S. Abdelhameed, "Insight into the interaction between the HIV-1 integrase inhibitor elvitegravir and bovine serum albumin: a spectroscopic study," Journal of Spectroscopy, vol. 2015, pp. 1-9, 2015.

[40] J.-H. Shi, J. Chen, J. Wang, Y.-Y. Zhu, and Q. Wang, "Binding interaction of sorafenib with bovine serum albumin: spectroscopic methodologies and molecular docking," Spectrochimica Acta Part A: Molecular and Biomolecular Spectroscopy, vol. 149, pp. 630-637, 2015.

[41] R. K. Scopes, "Measurement of protein by spectrophotometry at $205 \mathrm{~nm}$," Analytical Biochemistry, vol. 59, no. 1, pp. 277282, 1974.

[42] H. Xu, N. Yao, H. Xu, T. Wang, G. Li, and Z. Li, "Characterization of the interaction between eupatorin and bovine serum albumin by spectroscopic and molecular modeling methods," International Journal of Molecular Sciences, vol. 14, no. 7, pp. 14185-14203, 2013.

[43] A. S. Abdelhameed, A. H. Bakheit, H. K. AlRabiah, E. S. G. Hassan, and F. M. Almutairi, "Molecular interactions of AL3818 (anlotinib) to human serum albumin as revealed by spectroscopic and molecular docking studies," Journal of Molecular Liquids, vol. 273, pp. 259-265, 2019.

[44] S. Khatun and R. Riyazuddeen, "Probing of the binding profile of anti-hypertensive drug, captopril with bovine serum 
albumin: a detailed calorimetric, spectroscopic and molecular docking studies," Journal of Chemical Thermodynamics, vol. 126, pp. 43-53, 2018.

[45] J. Liu, Y. He, D. Liu et al., "Characterizing the binding interaction of astilbin with bovine serum albumin: a spectroscopic study in combination with molecular docking technology," RSC Advances, vol. 8, no. 13, pp. 7280-7286, 2018.

[46] M. Manjushree and H. D. Revanasiddappa, "A diversified spectrometric and molecular docking technique to biophysical study of interaction between bovine serum albumin and sodium salt of risedronic acid, a bisphosphonate for skeletal disorders," Bioinorganic Chemistry and Applications, vol. 2018, Article ID 6954951, 13 pages, 2018.

[47] T. Wani, A. Bakheit, A.-R. Al-Majed, M. Bhat, and S. Zargar, "Study of the interactions of bovine serum albumin with the new anti-inflammatory agent 4-(1,3-Dioxo-1,3-dihydro-2Hisoindol-2-yl)- $\mathrm{N}^{\prime}$-[(4-ethoxy-phenyl)methylidene] benzohydrazide using a multi-spectroscopic approach and molecular docking," Molecules, vol. 22, no. 8, p. 1258, 2017.

[48] A. Bortolotti, Y. H. Wong, S. S. Korsholm et al., "On the purported "backbone fluorescence" in protein threedimensional fluorescence spectra," RSC Advances, vol. 6, no. 114, pp. 112870-112876, 2016.

[49] Y. Z. Zhang, B. Zhou, X. P. Zhang, P. Huang, C. H. Li, and Y. Liu, "Interaction of malachite green with bovine serum albumin: determination of the binding mechanism and binding site by spectroscopic methods," Journal of Hazardous Materials, vol. 163, no. 2-3, pp. 1345-1352, 2009.

[50] Y.-C. Chen, H.-M. Wang, Q.-X. Niu, D.-Y. Ye, and G.-W. Liang, "Binding between Saikosaponin C and human serum albumin by fluorescence spectroscopy and molecular docking," Molecules, vol. 21, no. 2, p. 153, 2016.

[51] T. S. Banipal, A. Kaur, I. A. Khan, and P. K. Banipal, "Exploring the thermodynamics and conformational aspects of nicotinic acid binding with bovine serum albumin: a detailed calorimetric, spectroscopic and molecular docking study," RSC Advances, vol. 6, no. 41, pp. 34754-34769, 2016.

[52] A. S. Abdelhameed, A. H. Bakheit, F. M. Almutairi, H. AlRabiah, and A. A. Kadi, "Biophysical and in silico studies of the interaction between the anti-viral agents acyclovir and penciclovir, and human serum albumin," Molecules, vol. 22, no. 11, p. 1906, 2017.

[53] X. Zhang, L. Li, Z. Xu et al., "Investigation of the interaction of naringin palmitate with bovine serum albumin: spectroscopic analysis and molecular docking," PLoS One, vol. 8, no. 3, Article ID e59106, 2013. 

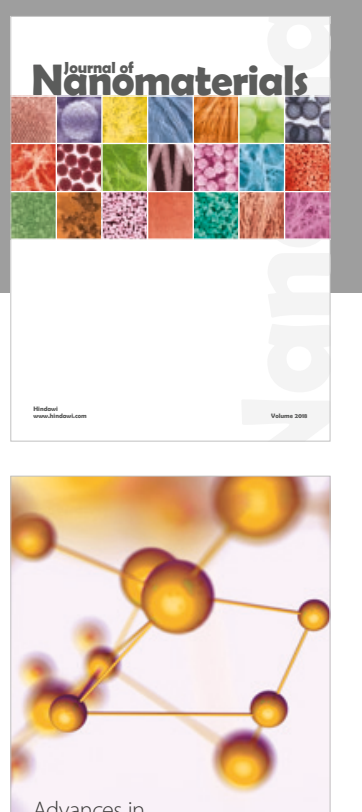

Physical Chemistry
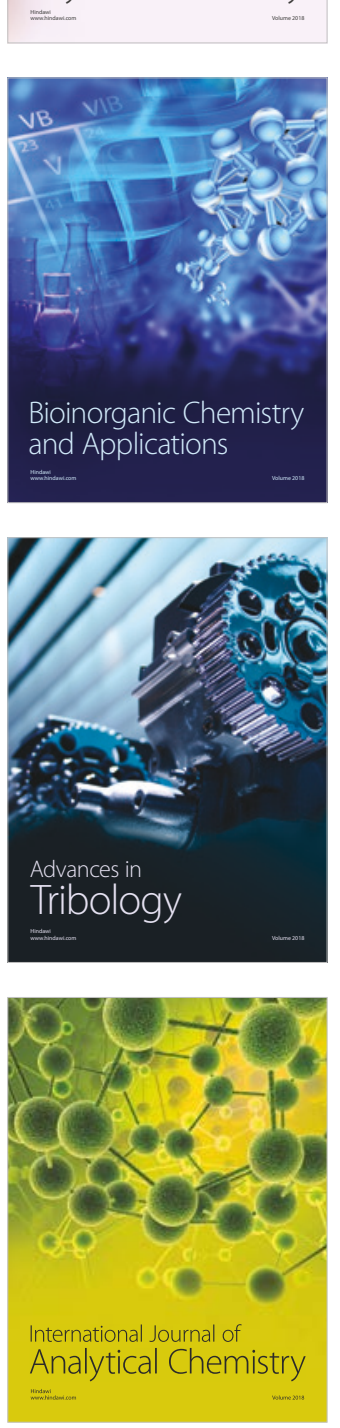

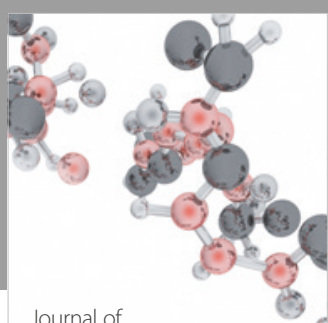

Analytical Methods

in Chemistry

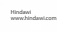

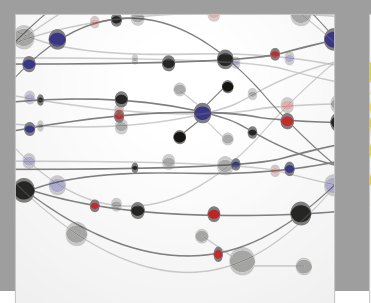

The Scientific World Journal

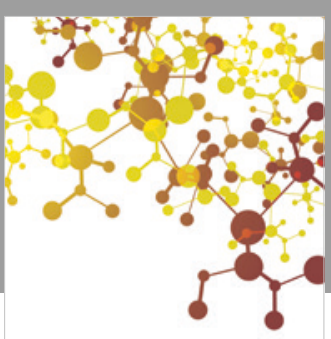

Journal of

Applied Chemistry
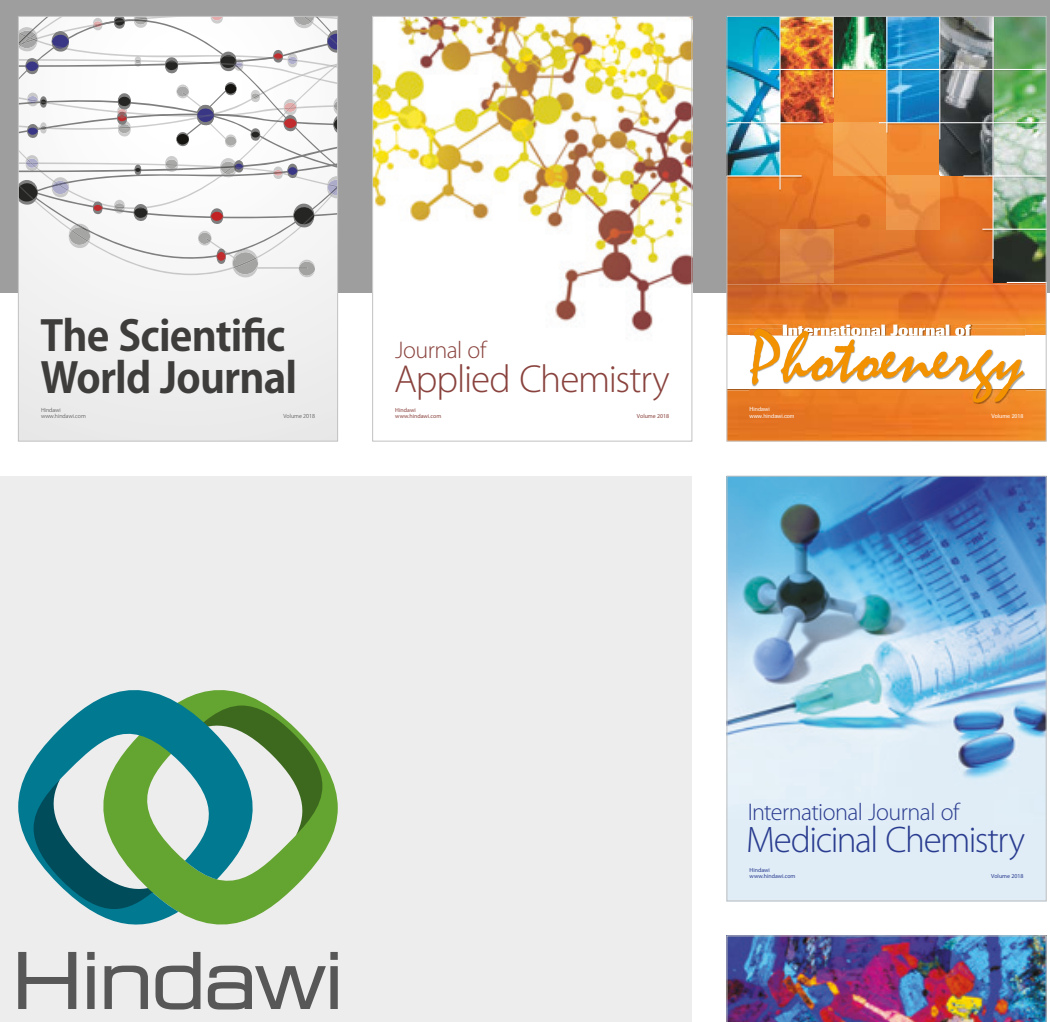

Submit your manuscripts at

www.hindawi.com
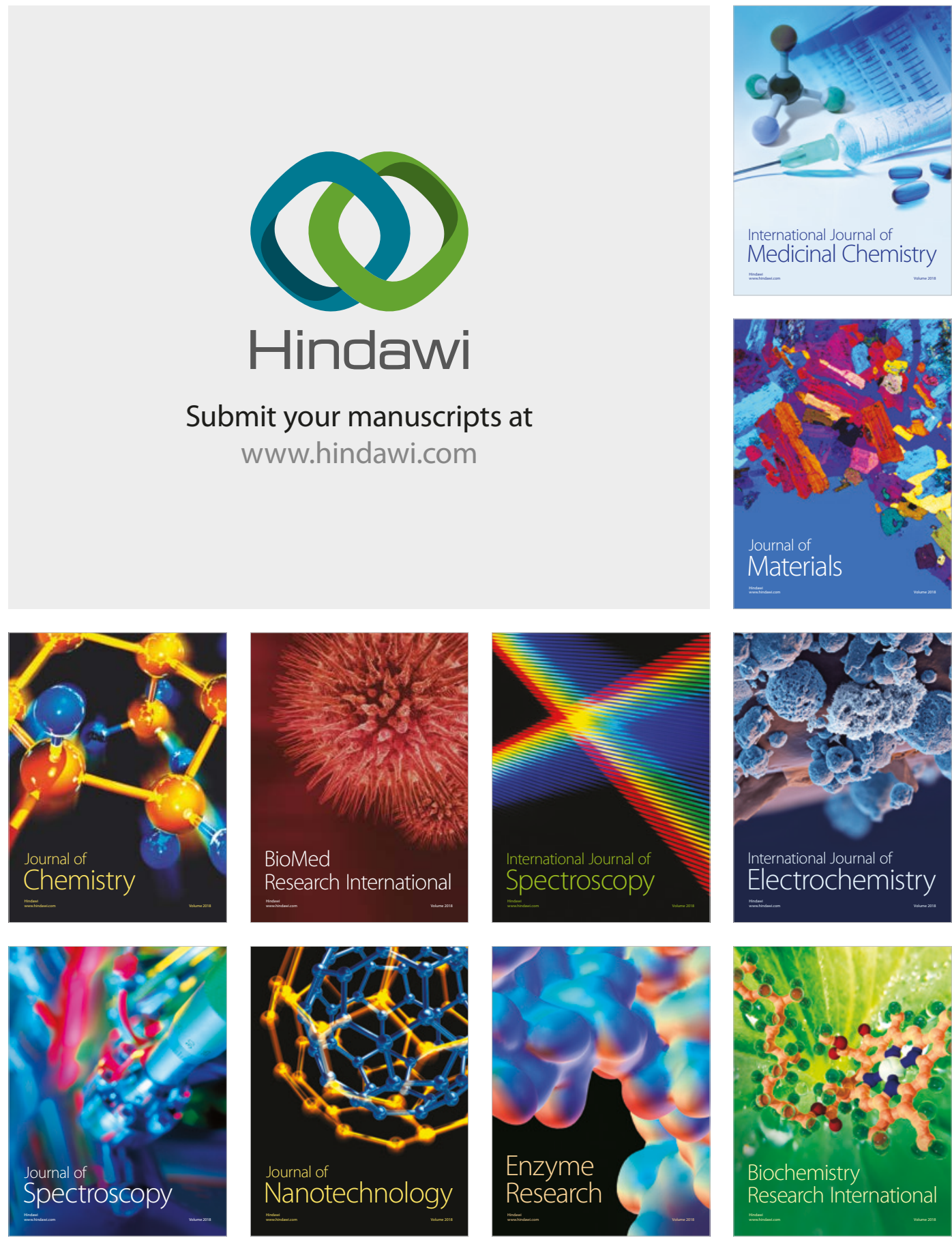
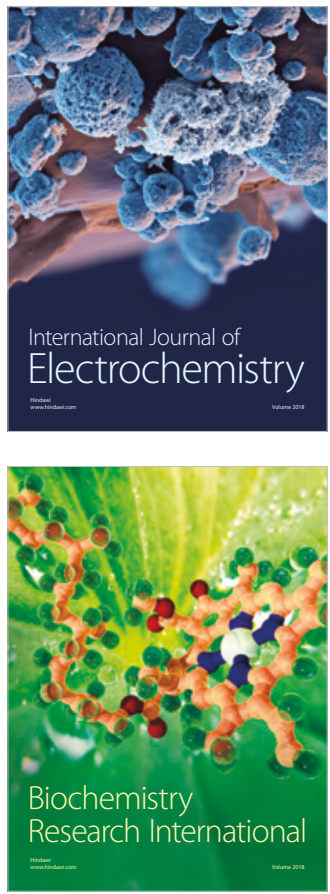